\title{
Causes and Effects of Child Sexual Abuse
}

\author{
${ }^{1}$ Shalini Gupta (Research Scholar), Ph.D. in Law \\ Sant Baba Bhag Singh University, Jalandhar
}

\begin{abstract}
Like many other social issues, Child Sexual abuse cases are increasing in modern society. At ground zero level it becomes difficult to manage the same. Child Sexual abuse is secret wrongdoing, but the biggest irony is that if the child wants to tell anyone about it, he is silenced for life. Children are frequently frightened to tell anybody regarding the wrongdoing. Many instances of misuse are not reported by the victim.
\end{abstract}

CSA leaves many bad effects on victims which include pain, fear, self-harm, sexual health, physical health, emotional and mental harm, Guilt and shame, Post-traumatic stress disorder, impaired brain development, suicide attempt, difficulties during adolescence, abusive behavior, and sexually transmitted diseases. The victim finds difficulty to make interpersonal relationships and intimate relationships with others due to the unforgettable experiences of the past.

CSA refers to the physical, mental, and emotional abuse of the child. The fundamental casualties of child sexual abuse are broken family children, sex worker's children, street children, and Child Labour. ${ }^{1}$ In India, there are various kinds of maltreatment in our society which may always not recognize. It greatly affects the Child's wellbeing. Besides that, it is increasing day by day. It is truly shocking for everyone.

\section{INTRODUCTION}

According to the World Health Organization definition, Child Sexual abuse means " It includes a child who is unable to give consent, under compulsion, fear or any other circumstances, not prepared physically, mentally or emotionally for sexual activities, any illegal activity, other activity which not relates with the moral values of the society, child trafficking, child prostitution, child pornography, and many other similar acts, which are done against the will of the child in it". ${ }^{2}$

[1]. Shahana Nasrin, Causes and effects of child abuse: an Analysis, Available at: https://www.academia.edu/31134316/Causes_and_Eff ects_of_Child_Abuse

[2]. World Health Organization, Report of the consultation on child abuse prevention (WHO/HSC/PVI/99.1) World Health Organization; Geneva (Switzerland): 1999. Available at: https://scholar.google.com/scholar_lookup?title=Repo rt+of+the+consultation+on+child+abuse+prevention+ (WHO/HSC/PVI/99.1)\&publication_year=1999

\author{
${ }^{2}$ Dr. Seema Garg, Assistant Professor \\ Sant Baba Bhag Singh University, Jalandhar
}

Sexual abuse of the children is not a new phenomenon but it is prevailing all around the world since the time immemorial. Every day a large number of children are sexually abused within the sphere of their own family. But it is not always in the news. The reason behind this is the fear as well as the impact of the incidence on the child's mind which restraint the child to tell about the incidence. Offensive and brutal behavior toward children is increasing day by day. CSA is a violation of the basic human rights of the child. It has some harsh physical and psychological results that affect the health, and overall personality of a child. $^{3}$

Child sexual abuse unfavorably influences the prosperity and well-being of a child and affects society's morals \& social values. Only sexuality is troublesome sufficient for individuals to deliberately manage, significantly less the possibility of children taking part in such exercises with grown-ups or each other. ${ }^{4}$ CSA is such a brutal and heinous crime where a powerful and elder person cannot control his emotions and take advantage of the innocence of a child for their sexual satisfaction and in most of the cases for financial gain.

CSA hurts the children in two way i.e. one is the physical act and the second is a psychological experience. The physical act involves both practices of touching and non-touching the victim. And in psychological experience, it mainly an abuse of power and authority, where to satisfy himself emotionally and sexually a perpetrator uses the child. And it hurts and confused the children that what is happening with them.

According to the data based on many studies, child sexual abuse had the worst effect on the victim's mind and body. At that moment, they are going through very difficult times that they even can't trust anyone to tell about their state of mind. The physical injury, as well as the injury caused to their mind, leaves enormous marks that cannot be erased. And there is no language that can indicate that a child has been sexually abused. What would be the immediate signs that the child is being sexually abused? There will be unexpected physical, emotional and

[3]. Malhotra, D.M., \& Srivastava, D.A. (2016). Child Sexual Abuse and Personality Development. Retrieved from www.imjdrr.com/downloads/3103201610.pdf

[4]. Gold S, Lucenko B, Elhai J, Swingle J, Sellers A (1999), A Comparison of psychological/ psychiatric symptomatology of women and men sexually abused as children. Child Abuse Neglect 23: 683-692 
behavioral changes in the child, ${ }^{5}$ and some of them are aggression, Hyperactivity, Hostility, Homosexuality, Alcohol and substance abuse, guilt, chronic pain, and many more.

\section{THE CAUSES OF CHILD SEXUAL ABUSE}

Indian tradition has always been patriarchal and dominating, because of which a child always remain in their protection and care. Moreover, they also use force on children to discipline them, and they think it is benefitted for child development. ${ }^{6}$

Much research proves that only single factors not responsible for child sexual abuse but other factors also responsible collectively for this repulsive crime. And they are:-

\section{$>$ Exploitation}

The exploitation of the children in Commercial or household work refers to child labor. This exploitation sometimes leads to sexual harassment. Because the child is in the hands of his employer and away from his family. And this exploitation is not limited to harassment or child labor, but because of it affects the physical, mental health of a child, his education, his morality, and his social development.

\section{Poverty}

Poverty is a serious cause of child sexual abuse. Most of the cases of sexual abuse come from poor families. Where it is a trend to sale the child to fulfill his daily needs. Parents often assume that because they have brought a child into the world, they have the right to give the child into bondage. ${ }^{8}$ It is not that all cases of child sexual abuse come only from poor families, whereas some of them also come from the middle class and wealthy families. Poor and needy children become victim to adult abusers, who pretend to help them but take advantage of them.

\section{Stress:}

Stress also an important cause of child sexual abuse. In today's life where one side several factors responsible for a human being to lead his life peacefully. On the other hand, some other factors responsible for making his life stressful. Such as unemployment, illness, poor living

[5]. Finkelhor D, Sexually Victimized children, Free Press: New York 1979.pp.76\&77.

[6]. INDIA COUNTRY REPORT ON CONVENTION ON THE RIGHTS OF THE CHILD, 1997. Available at: https://nhrc.nic.in/sites/default/files/ChildrenRights.pd $\mathrm{f}$

[7]. Report of the Consultation on Child Abuse Prevention, 29-31 March 1999, WHO, Geneva Available at: https://apps.who.int/iris/handle/10665/65900

[8]. Loveleen Kacker, Childhood Betrayed Child abuse and neglect in India, Thomson Press: india 2015.pp. 10. conditions, a larger family, low income, lack of facilities, inferiority complex, and many more.

\section{$>$ Lack of Education:}

Education is the key to a child's future. And lacking this will leads to great hardship for every individual. Uneducated children are more prone to abuse and become more vulnerable as they are beyond the protective reach of school and support services.

\section{$>$ Poor health problems}

Children living with a poor mental condition, learning disability or physical disability are more likely to report childhood sexual abuse as compare to others.

\section{$>$ Homelessness}

Children who are homeless are significantly more liable to have encountered sexual abuse. Some of them are at a very tender age and becomes the victim of sexual abuse. Domestic violence, sexual abuse, and other sorts of relational brutality are high between these homeless children.

\section{$>$ Unemployment}

Unemployment also a major cause of child sexual abuse. Even it can lead to divorce, Alcohol consumption, poverty, and many other factors. To cope with the stress of unemployment, an individual may lead to any form of abuse, and sexual abuse is one of them. Heterogeneous effects show that unemployment has a larger impact on young children. And if there is an increase in one unit of unemployment then ultimately increase in all forms of abuse. $^{9}$

\section{Acquaintances}

Children believe in the person with whom they are familiar and cannot resist his or her behavior easily, even though they find it uncomfortable. ${ }^{10}$

\section{Age of Parents}

The age of parents matters a lot in handling their child. If the parents are too young to take care of their children with proper protection then their children are at high risk. They do not properly take care of the requirements of their children. Because they do not know how to react in particular circumstances. So it is also a cause for sexual abuse.

[9]. Dan Brown, and Elisabetta De Cao, The Impact of Unemployment on Child Abuse and Neglect in the United States, Available at: http://conference.iza.org/conference_files/Gender_201 7/de_cao_e6099.pdf

[10]. Child Abuse and Child Sexual Abuse, available at: https://epgp.inflibnet.ac.in/Home/ViewSubject?catid= 32 


\section{Mental Health Problem}

A person suffering from depression or psychiatric illness is at a much higher risk of abusing and neglecting others. He has no control over his desires and in such a mental condition he sexually abused children.

\section{$>$ Lack of Self-Confidence}

Persons with a lack of self- confidence is more likely to abuse others because they often see themselves as worthless. Many studies prove that because of the human tendency a human being attracted to evil very early.

\section{EFFECTS OF CHILD SEXUAL ABUSE}

Child Sexual Abuse is an introduction of sexuality to an innocent child who is not aware of these feelings. Because it is not made for him, but when he attains maturity, he will be able to understand it with the help and supervision of his parents and guardians. But child sexual abuse ruins his entire life. It affects the life of a victim as well as society. It has a very long term negative effects which can't be defined by a few definitions.

There is no single parameter by which a child can measure sexual abuse committed on himself. Being a child he is unaware of some things which he knows with the passing of time, so when he is a victim of child sexual abuse, he creates different-different images in his mind while living under the shadow of fear. ${ }^{11}$

The effect of Child sexual abuse and disregard is regularly examined as far as physical, mental, conduct, and cultural outcomes. Physical results can show mental ramifications. Mental issues lead to hazard habits. For instance, Depression, anxiety, may make an individual bound to smoke, abuse alcohol, or unlawful medication uses. A long term practice of all these bad habits can prompt serious health issues, for example, sexually transmitted diseases, cancer, and many more.

In some cases the physical effects are temporary; but, the pain and mental trauma a child suffers leaves a long-term impact. Below are some outcomes researchers have identified:

\section{Fear:}

Child Sexual Abuse is such a disgusting act that shakes the mind of a child, and as a result of this, a child is always in the shadow of fear and never gets out of it. Fear by children of being taken away from their parents most childhood abuse goes unreported.

\section{Self-harm:}

Aggression towards self as in self-blame, self-harm, and suicide are common consequences of sexual abuse. Those people who were sexually abused in childhood are more inclined to commit suicide than a normal person.

[11]. Ganesh Indira Maya, "When Sexuality is violence", Voices for change: A Journal on Communication Development, Vol. 3 (1), April 1999. p.50-52.

\section{Sexual Health:}

Being explicitly manhandled as a child, particularly when that misuse isn't found, can prompt confounded thoughts regarding connections and sexual conduct. ${ }^{12}$

\section{Emotional and Mental harm:}

Sexual abuse includes many physical consequences for victims, such as transmitted diseases and pregnancy. These physical impacts add to the noteworthy emotional and mental harm imposed by the abuse. All these victims faced many problems, including depression, anxiety, eating disorders, and suicide attempts. Other effects of CSA are panic disorder, dissociative disorders, attentiondeficit/hyperactivity disorder, post-traumatic stress disorder, and reactive attachment disorder.

\section{Guilt and Shame:}

In most cases, the abuser succeeds in convincing the victim that it is due to his own mistake. Some habitual abusers repeat the abusive act again and again. It leaves marks on the body and soul of the victim, and he feels guilt and shame. And due to guilt and shame, he finds it difficult to tell anyone about the abuse. The bad experiences he received from that abuse, compels him to commit suicide. ${ }^{13}$

\section{Post-Traumatic Stress Disorder:}

CSA can greatly affect the child physically, psychologically, and sexually. It may have long term effects on the body of the child. After this traumatic event if a child receives multiple injuries on his body and soul and he is also neglected by their parents and caregivers, so there is a chance of developing post-traumatic stress disorder in the child. After the rejection of their wellwishers, they do not develop their ability to trust anyone. And lacking effective counseling turns them away from society.

\section{Impaired brain development:}

The initial years of a child's life have a big impact on their brain development. That is why sexual abuse at this age can be so harmful that a child's experiences can change their thoughts. It can result in an undeveloped brain. Another effect of this is that the child can lead to an increased risk of mental health issues like depression in later life as well as cognitive disorders including memory disablement.

\section{Physical health:}

A victim of child sexual abuse children have some kind of physical or mental health problem, and also have long-term health problems such as sexually transmitted diseases, heart disease, cancer, chronic lung disease, skeletal fractures, and liver disease.

[12]. I.Fayaz (2019).Child Abuse: Effects and Preventive Measures. International Journal of Indian Psychology, 7(2), 871-884. DIP:18.01.105/20190702,

[13]. Allnock, D, et al (2009) Sexual abuse and therapeutic services for children and young people: the gap between provision and need: full report. London: NSPCC. 


\section{Difficulties during adolescence:}

In many cases, we have seen that abused children are more likely to experience problems such as delinquency, teen pregnancy, low academic achievement, drug use, and mental health problems than others.

\section{Abusive behavior:}

The victim's behavior becomes abusive. He is not in a position to believe anyone and it affects his present as well as future life. It is estimated approximately one-third of abused children will eventually victimize their children.

\section{Interpersonal Relationships:}

One of the significant effects of CSA is that the child cannot maintain close loving relationships. And if the abuser is well known to the victim then it can affect the relationships between them. The victim finds it difficult to make healthy relationships with partners, family, and friends. They cannot tell the pain of their conscience to anyone, which has a bad effect on their relationship.

\section{Intimate relationships}

Child sexual abuse has a long-lasting effect on the mind of the victim. So it creates difficulties in forming intimate and trusting relationships. ${ }^{14}$ Because up to some extent it reminds the victim of her childhood sexual abuse. And the fear and agony he feels, because of that he is unable to talk about sexual abuse with his partner.

\section{CONCLUSION}

In light of the given facts and many previous studies gave the number of evidence that support our results and research question. Child sexual abuse is not only a problem for one society but the whole world. The outcome of child sexual abuse can result in both short and long term consequences ranging from social problems, emotional problems, cognitive problems, educational problems, Low self-esteem, and self-harm or sometimes it may lead to suicide. The abuser who exploiting the children adversely affect his life as well as ruined his future.

Most of the cases are reported in families, in schools, in the community, on the street, and in work situations. Many victims are too young or too vulnerable to disclose their experiences or to protect themselves. Even after having so many legal provisions and child welfare organizations, if this crime is increasing, then every person will have to step forward for it. There is a dire need for adequate child protection policies and preventive measures that protect the child from any type of abuse. Such policies provide a safe place where a child can be kept and work for the development of the child.

[14]. The impacts of child sexual abuse: a rapid evidence assessment, available at: https://www.iicsa.org.uk/publications/inquiry/interim/ nature-effects-child-sexual-abuse/effects-child-sexualabuse 